\title{
Computational fluid and mass transport on macro and micro scales in an artificial kidney
}

\author{
S. Eloot \& P. Verdonck \\ Institute for Biomedical Technology, Ghent University, Gent, Belgium
}

\begin{abstract}
The evaluation of dialyzer geometry was obtained by investigating transport processes and fluid properties inside the dialyzer. With computational fluid dynamics (CFD), a macroscopic as well as a microscopic model of the dialyzer was developed.

Blood and dialysate flow distributions were calculated in a macroscopic numerical model of a low flux hollow fiber dialyzer. Computer simulations were compared to flow field SPECT visualizations (Single Photon Emission Computerized Tomography). The derived local fluid velocities were further implemented in a three-dimensional microscopic computer model of a single hollow fiber with its surrounding membrane and dialysate compartment. Different equations govern blood and dialysate flow (Navier-Stokes), radial filtration flow (Darcy), and solute transport (convection-diffusion). Blood was modeled as a non-Newtonian fluid with a viscosity varying both in radial and axial direction. Dialysate flow was assumed as a laminar Newtonian flow with constant viscosity. The permeability characteristics of the asymmetrical polysulphone membrane were calculated from laboratory tests for forward and backfiltration.

The model was calibrated and validated in order to accurately calculate water removal as well as mass transport of small (urea) and middle molecules (vitamin B12 and inulin). Furthermore, the present microscopic CFD model was used to investigate the impact on the mass removal of dialyzer geometry and flow distributions.

Keywords: dialyzer, ultrafiltration, backfiltration, mass transport, convection diffusion, viscosity model, hemoconcentration, CFD.
\end{abstract}




\section{Introduction}

During the progression of renal failure, a host of solutes, normally cleared by the healthy kidneys, is retained in the body of the uremic patient. This retention gives rise to a progressive deterioration of physiologic functions and of the clinical condition [1]. Hemodialysis is one of the possible treatments to remove those solutes from the blood when the human kidneys have lost their native function. During this therapy, blood is pumped out of the body into an extracorporeal circuit that contains a hollow fiber dialyzer. The latter is built of thousands of small fibers with a diameter of approximately $200 \mu \mathrm{m}$ and a total area of $0.8-2.5 \mathrm{~m}^{2}$. Blood and dialysate are circulated counter currently at the interior and exterior of the fibers, respectively. Those fibers are constructed from a semi-permeable membrane, which permits the diffusive and/or convective passage of uremic solutes but restricts the transfer of blood proteins and cells from the blood towards the dialysate compartment.

Recently, the European Uremic Toxin Work Group published a comprehensive list of all uremic solutes known to date [2]. Based on their physicochemical characteristics, one can distinguish between three major groups of uremic retention solutes: small water-soluble compounds $(\mathrm{MW}<500)$, the protein-bound solutes ( $\mathrm{MW}$ also mostly <500), and the so-called middle molecules $(\mathrm{MW}>500)$.

While dialyzer manufacturers only provide information about their products as a black box, the present study aimed at optimizing dialyzer geometry by looking more in detail at transport processes and fluid properties inside the dialyzer using computational fluid dynamics (CFD). First, a macroscopic model to visualize blood and dialysate flow distributions was developed and validated using SPECT (Single Photon Emission Computed Tomography) medical imaging. Second, a microscopic CFD model was developed to describe flow and mass transport in a single fiber. After model calibration and validation, the impact on solute removal of a variable fiber length and diameter was assessed for small (urea MW60) and middle molecules (vitamin B12 MW1355 and inulin MW5200). Further on, the validated model was used to examine the effect of flow maldistribution by implementing the experimental SPECT results.

\section{Materials and methods}

\subsection{Macroscopic CFD model}

Because the fiber compartment is modeled as a porous medium, blood and dialysate flow were investigated using two separate models. The blood flow in the dialyzer housing (F6HPS, Fresenius Medical Care, Bad Homburg, Germany) is modeled with a three-dimensional finite volume model (Fluent 6, Sheffield, UK) of a quarter part of the dialyzer due to symmetry reasons (figure 1). As the inlet and outlet nozzles of the dialysate compartment are non-symmetrically placed on the dialyzer housing, a three-dimensional CFD model (Fluent 6, Sheffield, UK) of the entire dialyzer was developed to study dialysate flow (figure 1). 

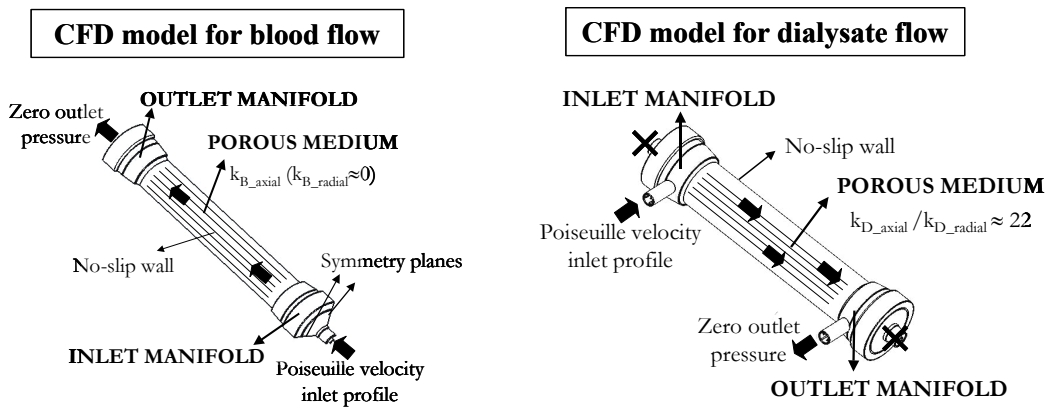

Figure 1: CFD model for blood flow (left panel) and dialysate flow (right panel) in a dialyzer.

In the inlet and outlet nozzles, and in the manifolds, continuity and NavierStokes equations are used, describing conservation of mass and momentum. The fiber compartment is modeled as a porous medium using Darcy's law with corresponding permeability proportion ratio in the different flow directions. The permeability characteristics of the fiber bundle were obtained from in vitro tests in which pressure drop and flow measurements were performed for flow inside the hollow fibers (blood compartment model), flow around the fibers in axial direction, and flow around the fibers in radial direction (dialysate compartment model). In the latter, an axial to radial permeability ratio of 22 was found [3].

In both CFD models, a parabolic velocity profile at the inlet nozzle and a zero pressure at the corresponding outlet nozzle are prescribed. Besides the symmetry boundaries, all other boundaries are defined as walls where no slip is assumed.

Blood was modeled as a Newtonian fluid with a density of $1054 \mathrm{~kg} / \mathrm{m}^{3}$ and a dynamic viscosity of $2.96 \mathrm{mPa}$.s derived from [4]:

$$
\mu=\mu_{\mathrm{p}} \cdot \exp (2.31 \cdot \mathrm{H})
$$

with plasma viscosity $\mu_{\mathrm{p}}$ equal to $1.3 \mathrm{mPa}$.s and the hematocrit of anemic blood $\mathrm{H}$ $35 \%$. As blood thickening due to ultrafiltration occurs along the dialyzer length, blood viscosity was assumed to increase linearly up to $4.10 \mathrm{mPa} . \mathrm{s}$, which corresponds to an overall ultrafiltration flow of $2 \mathrm{~L} / \mathrm{h}[5]$.

The fluid characteristics of the bicarbonate dialysate were derived from samples, taken from the dialyzer supply and drain, during clinical dialysis. Dynamic viscosity and density were determined using a capillary Ubbelohde viscosimeter (Schott, Germany), and a density-hydrometer-aerometer (Assistant, Germany), respectively. As it was found that both properties are not influenced by the dialysis session, dialysate flow was assumed as an incompressible, isothermal laminar Newtonian flow with a constant viscosity $(0.687 \mathrm{mPa} . \mathrm{s})$ and density $\left(1008 \mathrm{~kg} / \mathrm{m}^{3}\right)$ at body temperature.

\subsection{Validation using Medical Imaging Technique}

A new in vitro setup was built to visualize blood and dialysate flow through hemodialyzers using SPECT (Single Photon Emission Computed Tomography) 
imaging [3]. A steady state flow was accomplished in the compartment under study, while a computer controlled injection system was used for radioactive bolus injection in the dialyzer supply tubing. The dialyzer was centrally positioned in between the two and three-headed gamma camera for blood and dialysate flow visualizations, respectively. At the dialyzer outlet, flow rates were measured gravimetrically.

For the blood flow measurements, radioactive transport through the semipermeable membrane was avoided by injecting $10 \mathrm{~mL}$ boluses of 200000Da 99m-Technetium labeled MAA (Macro Aggregated Albumin). With the dialyzer fixed inside a two-headed gamma camera, planar dynamic 2D images were taken of the bolus passage. Assuming axisymmetrical flow in the blood compartment, the planar images were considered as taken at each view angle. After multiplication of the images over $360^{\circ}$ and after performing a filtered backprojection [6], a three-dimensional dynamic image was obtained.

Using water instead of blood in the dialyzer blood compartment, flow rates were adjusted to account for the difference in dynamic viscosity and density. To obey dimensional similarity between in vivo blood and in vitro water flow, Reynolds numbers Re (-) were kept equal in both models:

$$
\mathrm{Re}=\frac{\rho \cdot \mathrm{Q} \cdot \mathrm{d}}{\mu \cdot \varepsilon \cdot \mathrm{A}_{\mathrm{f}}}=\mathrm{constant}
$$

with $\rho$ fluid density $\left(\mathrm{kg} / \mathrm{m}^{3}\right)$, Q flow rate $\left(\mathrm{m}^{3} / \mathrm{s}\right)$, d fiber diameter $(\mathrm{m}), \mu$ dynamic viscosity (Pa.s), $\varepsilon$ porosity (-) and $\mathrm{A}_{\mathrm{f}}$ gross frontal area $\left(\mathrm{m}^{2}\right)$. Flow rates were adjusted with a factor 2.75 to account for the difference in density and viscosity. During investigation of the flow pattern in the blood compartment, the dialysate side was filled with fresh tap water at room temperature and hermetically closed.

For the dialysate flow visualizations, $10 \mathrm{~mL}$ boluses of $99 \mathrm{~m}-\mathrm{Tc}-\mathrm{DMSA}$ (Dimercaptosuccinic Acid, MW 281Da) tracer were injected, while pressurized air was forced simultaneously and counter-currently through the blood compartment to avoid water filtration and Technetium diffusion through the dialyzer membrane. 3D-acquisitions of the dialysate compartment were made by rotating the three-headed gamma camera over $120^{\circ}$ in $12^{\circ}$ increments. For each angular position, 2D planar intensity pictures of the bolus passage through the dialysate compartment were taken. By evaluating the images of the 10 measurements at different time steps, and by performing a filtered backprojection [6], a dynamic 3D image was constructed of the bolus propagation in the dialysate compartment.

For each time step, an intensity profile along the total dialyzer length was assessed. By analyzing the axial bolus intensity shift $(\Delta z)$ in between two considered timeframes $(\Delta \mathrm{t})$, the local axial velocity was calculated as $\Delta \mathrm{z} / \Delta \mathrm{t}[3]$.

\subsection{Microscopic CFD model}

\subsubsection{Model geometry}

A three-dimensional finite volume microscopic model of the blood-dialysate interface over the complete length of a dialyzer was developed (Fluent 6 Sheffield UK) [5]. Assuming the fibers spaced in a hexagonal lattice and based 
on symmetry, a twelfth part of one single fiber was isolated (figure 2). The parameter settings of the three-dimensional module were assessed for a high flux polysulphone dialyzer (F60, Fresenius Medical Care, Bad Homburg, Germany), characterized by a fiber inner diameter of $200 \mu \mathrm{m}$, membrane thickness of $40 \mu \mathrm{m}$ ( $1 \mu \mathrm{m}$ inner layer and $39 \mu \mathrm{m}$ bulk layer), and dialysate compartment dimensions (maximum radius $230 \mu \mathrm{m}$ ) calculated from fiber bundle density. The membrane module has an active length of $230 \mathrm{~mm}$ while inlet and outlet tubes (each $12.5 \mathrm{~mm}$ long) are integrated in the model. The mesh generation was performed using Gambit (Fluent - Sheffield UK). For the implementation in the numerical model, properties of the three compartments, blood, dialysate and the semipermeable membrane, are derived from literature and experimental investigations.

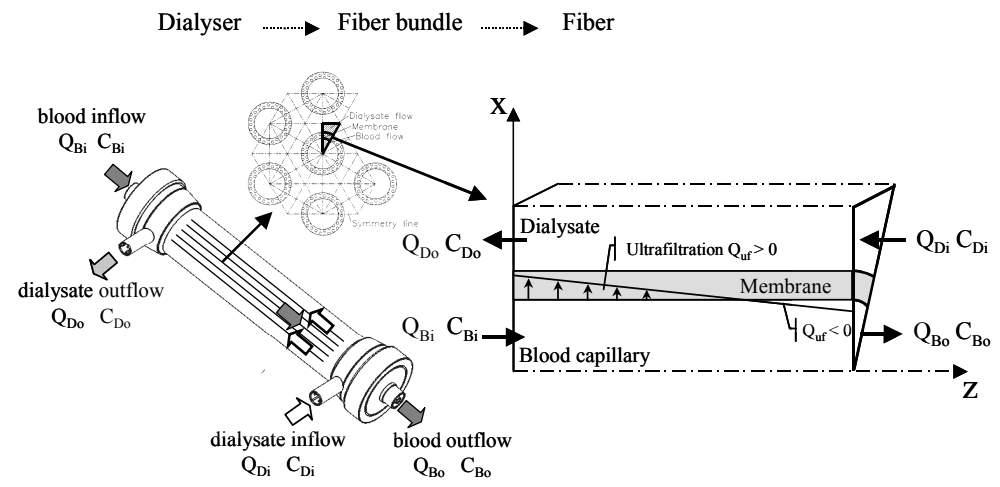

Figure 2: $\quad$ Schematic illustration of a hollow fiber dialyzer on macroscopic (dialyzer) and microscopic (fiber) level. Blood and dialysate inlet (subscript i) and outlet (subscript o) flows and concentrations are indicated as $\mathrm{Q}_{\mathrm{Bi}}, \mathrm{Q}_{\mathrm{Bo}}, \mathrm{Q}_{\mathrm{Di}}, \mathrm{Q}_{\mathrm{Do}}, \mathrm{C}_{\mathrm{Bi}}, \mathrm{C}_{\mathrm{Bo}}, \mathrm{C}_{\mathrm{Di}}$, and $\mathrm{C}_{\mathrm{Do}}$.

\subsubsection{Blood properties}

As ultrafiltration takes place over the length of the dialyzer, water is removed from the blood resulting in a decrease of the plasma volume fraction, such that the hematocrit as well as the blood viscosity value is augmented. The influence on viscosity of the local shear rate and hematocrit is taken into account using Quemada's equation [7]:

$$
\mu=\frac{\mu_{\mathrm{p}}}{(1-1 / 2 \mathrm{k} \cdot \mathrm{H})^{2}}
$$

Parameter $\mathrm{k}$ is function of the intrinsic viscosities $\mathrm{k}_{0}(\mathrm{H})$, characterizing the red blood cell aggregation at zero shear stress, $\mathrm{k}_{\propto}(\mathrm{H})$, describing the orientation and deformation of red blood cells at important shear stress, and the shear rate $\gamma$ [7]. For a fixed hematocrit, viscosity decreases with increasing shear rate, whereas for a fixed shear rate, viscosity increases with hematocrit.

Blood flowing through small capillaries exhibits a redistribution of the red blood cells in such a way that a plasma-skimming layer can be observed near the 
wall while red blood cells are concentrated in the centre. Fahraeus and Lindqvist [8] described the effect of this non-uniform cell distribution on the flow by defining an apparent blood viscosity for use in the Haegen-Poiseuille equation. The radial variation of the hematocrit was deduced by Lerche and Oelke [9] using a parameter $\mathrm{n}$ that describes the degree of plasma skimming: nonuniformity of cell distribution increases with decreasing $n$. This parameter is determined iteratively as a function of the hematocrit using a three-dimensional CFD model, such that the obtained viscosity for flow in a small tube matches literature results of the apparent viscosity.

Since plasma density $\left(1030 \mathrm{~kg} / \mathrm{m}^{3}\right)$ differs from the density of platelets and blood cells $\left(1090 \mathrm{~kg} / \mathrm{m}^{3}\right)$, the density of blood $\rho_{\text {blood }}\left(\mathrm{kg} / \mathrm{m}^{3}\right)$ varies with the local hematocrit $\mathrm{H}(-)$ :

$$
\rho_{\text {blood }}=1030 .(1-\mathrm{H})+1090 . \mathrm{H}
$$

\subsubsection{Dialysate properties}

For the bicarbonate dialysis fluid, viscosity and density as found with the earlier described clinical tests were used (section 2.1).

\subsubsection{Membrane characteristics}

The permeability characteristics of the membrane were obtained from laboratory tests in which a dialysate flow was forced through the membrane. The ultrafiltration coefficient, $\mathrm{K}_{\mathrm{UF}}$, was calculated from flow, $\mathrm{Q}_{\mathrm{UF}}$, and transmembrane pressure, TMP, measurements. Furthermore, the overall hydraulic membrane permeability $\mathrm{k}_{\mathrm{m}}\left(\mathrm{m}^{2} / \mathrm{s} . \mathrm{Pa}\right)$ was derived from the ultrafiltration coefficient, $\mathrm{K}_{\mathrm{UF}}\left(\mathrm{m}^{3} / \mathrm{s} . \mathrm{Pa}\right)$, membrane surface, $\mathrm{A}\left(\mathrm{m}^{2}\right)$, and membrane thickness, $\mathrm{d}_{\mathrm{m}}(\mathrm{m})$ :

$$
\mathrm{k}_{\mathrm{m}}=\mathrm{K}_{\mathrm{UF}} \cdot \frac{\mathrm{d}_{\mathrm{m}}}{\mathrm{A}}
$$

The tests were done for forward and backfiltration using sterile dialyzers (overall permeability $7950 \mathrm{~nm}^{2} / \mathrm{s} . \mathrm{Pa}$ ) as well as samples in which a protein layer was induced on the membrane (overall permeability $3650 \mathrm{~nm}^{2} / \mathrm{s} . \mathrm{Pa}$ ) simulating a clinical session [10]. The permeability of the sterile inner layer $k_{i}$ (thickness $d_{i}$ ) and of the bulk layer $k_{b}$ (thickness $d_{b}$ ) were implemented as a series of two resistances, whereas the influence of a protein layer on the overall membrane permeability was incorporated as a higher resistive inner layer (lower $\mathrm{k}_{\mathrm{i}}$ ):

$$
\frac{\mathrm{d}_{\mathrm{m}}}{\mathrm{k}_{\mathrm{m}}}=\frac{\mathrm{d}_{\mathrm{b}}}{\mathrm{k}_{\mathrm{b}}}+\frac{\mathrm{d}_{\mathrm{i}}}{\mathrm{k}_{\mathrm{i}}}
$$

\subsubsection{Governing equations}

In the blood and dialysate compartment, conservation of mass and momentum are described by the three-dimensional steady incompressible continuity and Navier-Stokes equations, using the local and constant viscosity and density for blood and dialysis fluid, respectively. Transmembrane water transport, function of the membrane permeability $(\mathrm{k})$ and the local oncotic pressure, is described by the Darcy equation for porous media. 
Knowing the velocities in all nodes of the finite volumes, the mass transfer can be calculated with the stationary convection-diffusion equation in the absence of a source or sink reaction:

$$
\mathrm{S} \cdot(\overline{\mathrm{u}} \bullet \bar{\nabla} \mathrm{C})-\bar{\nabla}\left(\mathrm{D}_{\mathrm{S}} \cdot \bar{\nabla} \mathrm{C}\right)=0
$$

$\mathrm{D}_{\mathrm{S}}$ represents the solute diffusion coefficient $\left(\mathrm{m}^{2} / \mathrm{s}\right)$ and $\mathrm{C}$ the solute concentration $\left(\mathrm{mol} / \mathrm{m}^{3}\right)$. Although this equation is valid for all domains, note that the diffusion coefficient $\mathrm{D}_{\mathrm{S}}$ is different for the three domains. Furthermore, $\mathrm{S}$ can deviate from unity in the membrane domain when solute transport through the membrane is hampered [11-13]. In the present study, solutes of distinct molecular weight were investigated. Urea (MW60) was used as marker for the small water-soluble solutes, while vitamin B12 (MW1355) and inulin (MW5200) were used as middle molecule markers with a sieving coefficient equal to unity for the considered high flux polysulphone membrane.

\subsubsection{Model Boundary Conditions}

In the blood and dialysate compartment, a constant inlet velocity is given, while outlet conditions are specified either as outlet pressures or as a flow percentage distribution in both compartments to apply the desired ultrafiltration flow. Oncotic pressure, which is exerted by the plasma proteins and opposes the hydrostatic transmembrane pressure, is implemented as a discontinuous local pressure drop at the skin-bulk interface. Because of the difficulty to induce in vitro a stable protein layer on the membrane [10], initial oncotic pressure from literature $(25 \mathrm{mmHg})$ was used $[13,14]$. Moreover, as hemoconcentration takes place in axial direction, the oncotic pressure is varying with hematocrit. Because the smallest blood-membrane-dialysate entity is isolated, all other boundaries are symmetry planes.

\subsubsection{Calibration and validation of the diffusivities}

While the solute diffusion coefficients in blood and dialysate were known from literature, membrane diffusivity was derived from the inlet and outlet blood $\left(\mathrm{C}_{\mathrm{Bi}}\right.$ and $\left.\mathrm{C}_{\mathrm{Bo}}\right)$ and dialysate $\left(\mathrm{C}_{\mathrm{Di}}\right.$ and $\left.\mathrm{C}_{\mathrm{Do}}\right)$ concentrations. Blood concentrations $(\mathrm{mol} / \mathrm{L})$ were assessed from the clearance equation:

$$
\mathrm{K}=\frac{\left(\mathrm{C}_{\mathrm{Bi}}-\mathrm{C}_{\mathrm{Bo}}\right)}{\mathrm{C}_{\mathrm{Bi}}} \cdot \mathrm{Q}_{\mathrm{B}}
$$

where the manufacturer reports $\mathrm{K}$ values for given blood/dialysate flow combinations $[15,16]$. Dialysate concentrations $(\mathrm{mol} / \mathrm{L})$ were calculated from the mass balance of the dialyzer [17]:

$$
\left(\mathrm{C}_{\mathrm{Bi}}-\mathrm{C}_{\mathrm{Bo}}\right) \cdot \mathrm{Q}_{\mathrm{B}}=\left(\mathrm{C}_{\mathrm{Do}}-\mathrm{C}_{\mathrm{Di}}\right) \cdot \mathrm{Q}_{\mathrm{D}}
$$

Although the concentration difference between blood and dialysate, $\Delta \mathrm{C}$, will decrease exponentially along the dialyzer length, a linear approximation is allowed for low and middle molecules [18]:

$$
\frac{\mathrm{d}(\Delta \mathrm{C})}{\mathrm{dz}}=\frac{\Delta \mathrm{C}_{\mathrm{i}}-\Delta \mathrm{C}_{\mathrm{o}}}{\mathrm{L}}
$$

With $\Delta \mathrm{C}_{\mathrm{i}}$ and $\Delta \mathrm{C}_{\mathrm{o}}$ the blood-dialysate concentration difference at the blood inlet and outlet, respectively. 
By multiplying both terms with the mass flux $\mathrm{J}$ (mol/s), as defined by Fick's law:

$$
\mathrm{J}=\mathrm{K}_{0} \cdot \mathrm{A} \cdot \Delta \mathrm{C}
$$

and after integration of equation 10 and solving it for the mass flux $\mathrm{J}$, clearance $K$ can then be written as a function of the mass transfer coefficient $K_{0}(\mathrm{~m} / \mathrm{s})$, which is the reciprocal of total resistance $\mathrm{R}_{0}$, and of the logarithmic mean concentration difference $\Delta \mathrm{C}_{\operatorname{lm}}[17]$ :

$$
\mathrm{K}=\frac{\mathrm{K}_{0} \cdot \mathrm{A}}{\mathrm{C}_{\mathrm{Bi}}} \cdot \Delta \mathrm{C}_{\mathrm{lm}}=\frac{1}{\mathrm{R}_{0}} \cdot \frac{\mathrm{A}}{\mathrm{C}_{\mathrm{Bi}}} \cdot \frac{\left(\mathrm{C}_{\mathrm{Bi}}-\mathrm{C}_{\mathrm{Do}}\right)-\left(\mathrm{C}_{\mathrm{Bo}}-\mathrm{C}_{\mathrm{Di}}\right)}{\ln \left(\frac{\mathrm{C}_{\mathrm{Bi}}-\mathrm{C}_{\mathrm{Do}}}{\mathrm{C}_{\mathrm{Bo}}-\mathrm{C}_{\mathrm{Di}}}\right)}
$$

Furthermore, as the mass transfer coefficient $\mathrm{K}_{0}$ for radial diffusive mass transfer (in $\mathrm{x}$-direction) is equal to $\mathrm{D}_{S} / \Delta \mathrm{x}$, membrane diffusivity $\mathrm{D}_{M}\left(\mathrm{~m}^{2} / \mathrm{s}\right)$ can be derived from total resistance $R_{0}$ and the convective mass transfer coefficients $1 / R_{B}$ and $1 / \mathrm{R}_{\mathrm{D}}(\mathrm{m} / \mathrm{s})$ :

$$
\mathrm{R}_{0}=\mathrm{R}_{\mathrm{B}}+\mathrm{R}_{\mathrm{M}}+\mathrm{R}_{\mathrm{D}}=\frac{\Delta \mathrm{x}_{\mathrm{B}}}{\mathrm{D}_{\mathrm{B}}}+\frac{\Delta \mathrm{x}_{\mathrm{M}}}{\mathrm{D}_{\mathrm{M}}}+\frac{\Delta \mathrm{x}_{\mathrm{D}}}{\mathrm{D}_{\mathrm{D}}}
$$

$R_{B}, R_{M}$, and $R_{D}$ represent the blood-side, membrane and dialysate-side resistance, respectively. $\Delta \mathrm{x}_{\mathrm{B}}$ and $\Delta \mathrm{x}_{\mathrm{D}}$ symbolize a characteristic distance for diffusion in the blood and dialysate domain, while $\Delta \mathrm{x}_{\mathrm{M}}$ is the membrane thickness. As $\Delta \mathrm{x}_{\mathrm{B}}$ and $\Delta \mathrm{x}_{\mathrm{D}}$ were not a priori known, the diffusion coefficient in the membrane for a particular solute was derived iteratively until the clearance as found with the simulations matches the manufacturer's data for a $\mathrm{Q}_{\mathrm{B}} / \mathrm{Q}_{\mathrm{D}}$ ratio equal to $250 / 500 \mathrm{~mL} / \mathrm{min}$. The power of the numerical model was checked performing simulations for a $\mathrm{Q}_{\mathrm{B}} / \mathrm{Q}_{\mathrm{D}}$ equal to $300 / 500 \mathrm{~mL} / \mathrm{min}$, and comparing the numerically derived clearance value with the manufacturer's data $[15,16]$.

\subsection{Parameter study}

With the extended finite volume model, which was validated with ex vivo experiments [19], a parameter study was performed varying blood and dialysate flows $(150-350 \mathrm{~mL} / \mathrm{min}$ and $300-800 \mathrm{~mL} / \mathrm{min}$ ) and dialyzer geometry (axial as well as radial dimensions). Finally, the impact of dialyzer dimensions on dialyzer clearance was studied by changing fiber diameter and length in a wide range, while keeping a constant fluid velocity.

\subsection{Impact of flow distribution on mass transport}

The impact of the dialysate flow maldistribution on solute transfer efficiency was evaluated numerically by implementing the local velocities as obtained from the SPECT measurements (paragraph 2.2). Mass transfer calculation was performed for urea and vitamin B12 in the case of maximum $(20.5 \mathrm{~mm} / \mathrm{s})$ and minimum dialysate flow velocity $(4.3 \mathrm{~mm} / \mathrm{s})$, instead of the mean dialysate velocity of $12.1 \mathrm{~mm} / \mathrm{s}$. Meanwhile, blood flow was considered homogeneously distributed, and a Poiseuille velocity profile with mean velocity of $17.3 \mathrm{~mm} / \mathrm{s}$ was used at the blood inlet, corresponding to a uniform overall blood flow of $300 \mathrm{~mL} / \mathrm{min}$. 


\section{Results}

\subsection{Macroscopic flow visualization}

The CFD results showed a homogeneous blood flow distribution in the fibers, while vortices can be remarked at the inlet manifold. Although vortices are also observed in the dialysate compartment at the transition of the inlet nozzle with the dialysate distribution ring, an axisymmetrical flow pattern is found around the fibers (figure 3 ).

The validation with SPECT measurements also showed a homogeneous velocity profile in the fiber compartment. Activity accumulation was however noticed in both manifolds and might be due to the adhesion of the Macro Aggregated Albumin to the plastic dialyzer capsule. Moreover, these accumulation sites correspond with regions of low blood velocity and possible blood clotting.

In contrast with the numerical results, SPECT imaging of dialysate flow resulted in a skewed velocity profile with a maximum near the nozzles-side housing, while a minimum value was located down the dialyzer axis (at 23$25 \mathrm{~mm}$ vertical distance from the inlet nozzle) (figure 3). As a consequence, at the opposite site of inlet and outlet nozzles, non-efficient sites with respect to mass transport are observed [20]. Furthermore, a non-homogeneous velocity distribution was also observed in the plane perpendicular to the plane along the nozzles. This implies that the non-homogeneous velocity distribution is not only due to the flow distribution near the dialyzer inlet but also to the preferential flow channeling resulting from fiber twisting. Because of this, the discrepancy between the CFD and SPECT results might be attributed to the optimistic assumption in the CFD model of a homogeneous radial permeability over an entire cross section. Furthermore, the CFD model can be calibrated by implementing local permeabilities of the fiber bundle, as derived from the SPECT results.

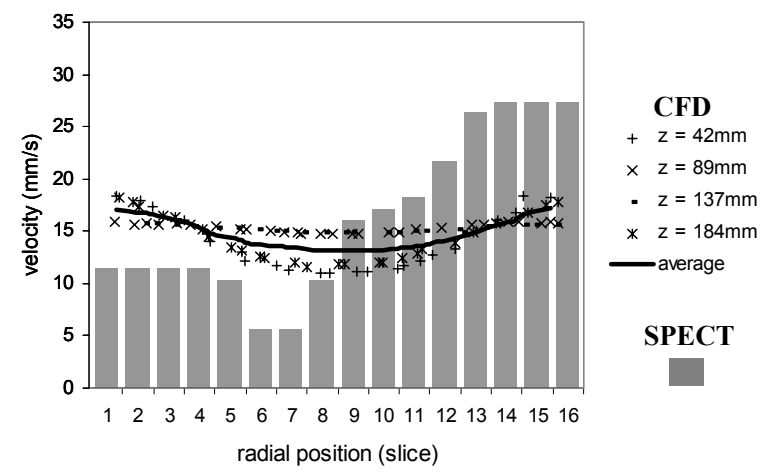

Figure 3: Radial distribution of axial dialysate velocity as computed with CFD for 4 different axial $z$ positions compared to average. The CFD results are also compared to mean bolus peak velocity (bars) as measured with SPECT. 


\subsection{Microscopic flow and mass transport}

Assuming a constant blood and dialysate inlet flow of 250 and $500 \mathrm{~mL} / \mathrm{min}$, respectively, blood and dialysate outlet pressures of $10 \mathrm{kPa}(75 \mathrm{mmHg})$ and $5 \mathrm{~Pa}$ $(0.04 \mathrm{mmHg})$, respectively, and an initial oncotic pressure of $3.33 \mathrm{kPa}(25 \mathrm{mmHg})$ $[13,14]$, the pressure distribution renders an overall ultrafiltration flow of $45 \mathrm{~mL} / \mathrm{min}$ while no backfiltration occurs.

As blood, with an initial viscosity of $3 \mathrm{mPa} . \mathrm{s}$, flows through the dialyzer, the water removal causes hemoconcentration. As a consequence, the hematocrit shows an axial variation from its initial value $30 \%$ at blood entrance up to $42 \%$ at the outlet, resulting in a mean viscosity increase from $3 \mathrm{mPa} . \mathrm{s}$ to $4.5 \mathrm{mPa}$.s. The plug flow of blood cells at the axis (maximum viscosity $7.5-11.8 \mathrm{mPa} . \mathrm{s}$ ) and the plasma layer near the membrane wall (viscosity $1.3 \mathrm{mPa} . \mathrm{s}$ ) demonstrates the radial variation of the blood viscosity (figure 4).

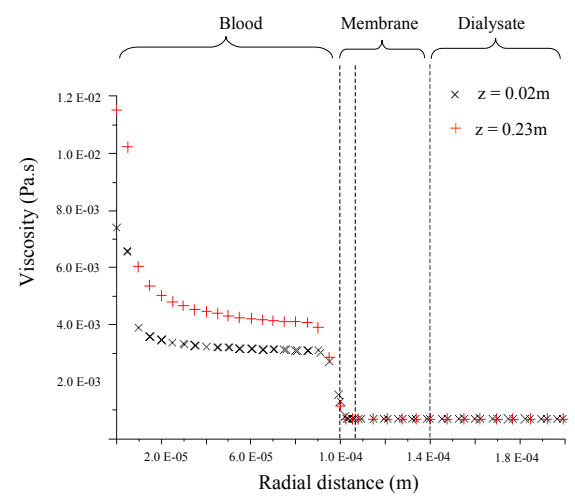

Figure 4: Radial viscosity distribution at blood inlet $(\mathrm{x})$ and outlet $(+)$ section.

The oncotic pressure, varying with the local hematocrit, increases from its initial value $3.33 \mathrm{kPa}(25 \mathrm{mmHg})$ up to $4.20 \mathrm{kPa}(31 \mathrm{mmHg})$. Due to this oncotic pressure opposing the hydraulic driving pressure, ultrafiltration flow is decreased by $28 \%$.

Due to ultrafiltration, one may expect a deviation from the linear flowpressure drop profile described by Poiseuille as well as from the parabolic velocity profile. Nevertheless, for an ultrafiltration flow of $45 \mathrm{~mL} / \mathrm{min}$ in a dialyzer module of $230 \mathrm{~mm}$ in length, the pressure distribution in the blood compartment deviates only slightly from linearity (figure 5), while the same is true for the parabolic velocity profile.

With respect to mass transfer, figure 6 shows the concentration profiles for urea, vitamin B12, and inulin in a standard F60 dialyzer with overall blood and dialysate flows of 250 and $500 \mathrm{~mL} / \mathrm{min}$, respectively. The radial concentration variation, most pronounced for inulin, illustrates the lower diffusivities in blood and dialysate compared to urea. Comparing outlet with inlet solute 
concentrations, clearances of 213,126 , and $61 \mathrm{ml} / \mathrm{min}$ were found for urea, vitamin $\mathrm{B} 12$, and inulin, corresponding to the data as provided by the manufacturer.

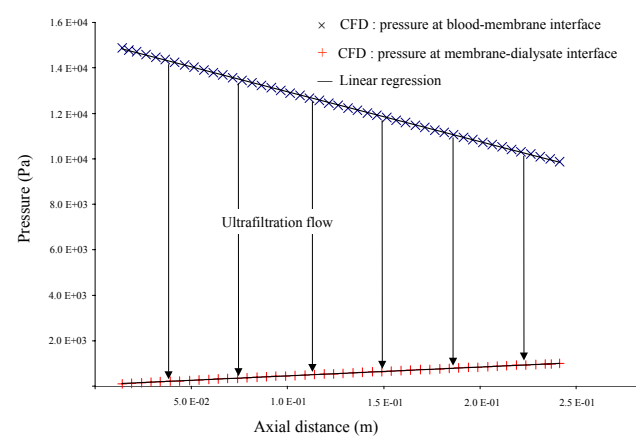

Figure 5: Axial pressure distribution in blood $(\mathrm{x})$ and dialysate $(+)$ compartment.
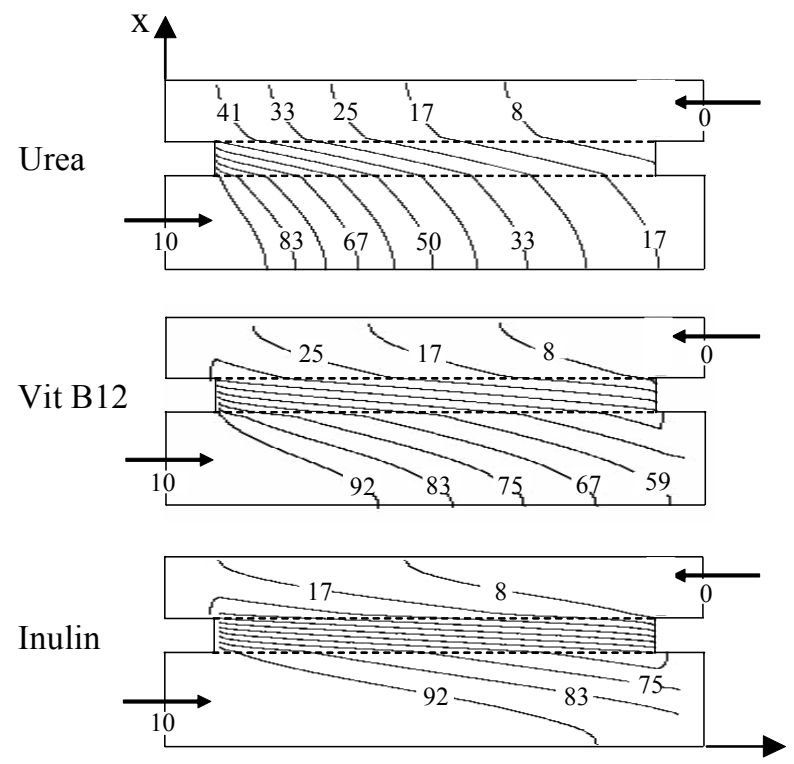

Figure 6: Concentration profiles in the dialyzer fiber (diameter $200 \mu \mathrm{m}$ and length $230 \mathrm{~mm}$ ) for urea (upper panel), vitamin B12 (middle panel), and inulin (lower panel). The relative blood start concentration was 100 , while blood and dialysate flows were 250 and $500 \mathrm{~mL} / \mathrm{min}$. 


\subsection{Results of the parameter study}

Increasing blood and dialysate flow rate while keeping the geometrical and blood characteristics constant, the blood viscosity and hematocrit percentage variations are reduced exponentially. Moreover, hematocrit increase is even more expressed than viscosity increase if blood flow rates over $220 \mathrm{~mL} / \mathrm{min}$ are considered. With respect to fiber length, blood viscosity as well as hematocrit increases are smaller for shorter fibers $(180 \mathrm{~mm})$ compared with the standard ones $(230 \mathrm{~mm})$. Further lengthening of fibers $(280 \mathrm{~mm})$ however does not change blood property variations significantly. Varying the radial dimensions (fiber inner diameter $150-200-250 \mu \mathrm{m})$, blood property variations are from the same magnitude of those found in the case of axial variation. Clearances were found enhanced by $13 \%$ (urea), 50\% (vitamin B12), and 89\% (inulin) for a fiber twice as long as a standard one, and by $5.5 \%$ (vitamin B12) and $21 \%$ (inulin) for a fiber diameter of $150 \mu \mathrm{m}$ instead of $200 \mu \mathrm{m}$. In general, the impact of fiber dimensions was more pronounced for the middle molecules compared to urea.

\subsection{Influence of flow distribution on mass transport}

While the observed maximum dialysate velocity resulted in a clearance increase of 1.3 and $12 \%$ for urea and vitamin B12, the minimum dialysate velocity deteriorated solute removal by 12 and $28 \%$, respectively. By calculating the clearances for intermediate blood-dialysate flow combinations, and by integration over the cross section, an overall decrease in solute removal efficiency by 3.8 and $4.4 \%$ was obtained for urea and vitamin B12, respectively.

\section{Conclusion}

In order to define regions characterized by diminished mass transfer efficiency, the existence of non-uniform flow in both the blood and dialysate compartment was investigated by computational fluid dynamics validated with SPECT imaging technique. With both techniques, a fully homogeneously distributed blood flow was found, while a discrepancy was observed for the dialysate flow in the case a constant fiber bundle permeability was modeled numerically. The SPECT results can be applied for validation of the CFD model with respect to the fiber bundle permeabilities, such that the validated CFD model can be further used for new dialyzer design and optimization. Furthermore, local velocities can be implemented in a microscopic model.

This microscopic CFD model incorporates blood, dialysate, and membrane flow allowing an accurate investigation of the fluid properties, solute concentrations, and the presence and localization of backfiltration. The hydraulic permeability of the dialyzer is based on a more accurate method than in previous ex vivo studies and blood is modeled as a non-Newtonian fluid with properties varying in radial as well as axial direction. Furthermore, the model allows calculating concentration profiles inside the dialyzer and related solute clearances. After validation of the CFD model, different parameters such as geometrical and fluid properties were investigated. 


\section{References}

[1] Vanholder R, Glorieux G, De Smet R, Lameire N: New insights in uremic toxins. Kidney Int Suppl:S6-10, 2003.

[2] Vanholder R, De Smet R, Glorieux G, Argiles A, Baurmeister U, Brunet P, Clark W, Cohen G, De Deyn PP, Deppisch R, Descamps-Latscha B, Henle T, Jorres A, Lemke HD, Massy ZA, Passlick-Deetjen J, Rodriguez M, Stegmayr B, Stenvinkel P, Tetta C, Wanner C, Zidek W: Review on uremic toxins: classification, concentration, and interindividual variability. Kidney Int 63:1934-1943, 2003.

[3] Eloot S, D'Asseler Y, De Bondt P, Verdonck P: Combining SPECT medical imaging and computational fluid dynamics for analyzing blood and dialysate flow in hemodialyzers. Int J Artif Organs in press, 2005.

[4] Mockros LF, Leonard R: Compact cross-flow tubular oxygenators. Trans Am Soc Artif Intern Organs 31:628-633, 1985.

[5] Eloot S, De Wachter D, Van Tricht I, Verdonck P: Computational flow modeling in hollow-fiber dialyzers. Artif Organs 26:590-599, 2002.

[6] Kak AC, Slaney M: Principles of computerized tomographic imaging. New York, IEEE Press, 1988.

[7] Quemada D: General features of blood circulation in narrow vessels, in Arteries and arterial blood flow: biological and physiological aspects, edited by Rodkiewicz CM, Wien, Springer-Verlag, 1983.

[8] Gaehtgens P: Flow of blood through narrow capillaries: rheological mechanisms determining capillary hematocrit and apparent viscosity. Biorheology 17:183-189, 1980.

[9] Lerche D, Oelke R: Theoretical model of blood flow through hollow fibres considering hematocrit-dependent, non-Newtonian blood properties. Int J Artif Organs 13:742-746, 1990.

[10] Eloot S, De Wachter D, Vienken J, Pohlmeier R, Verdonck P: In vitro evaluation of the hydraulic permeability of polysulfone dialysers. Int $J$ Artif Organs 25:210-216, 2002.

[11] Colton CK, Henderson LW, Ford CA, Lysaght MJ: Kinetics of hemodiafiltration. I. In vitro transport characteristics of a hollow-fiber blood ultrafilter. J Lab Clin Med 85:355-371, 1975.

[12] Henderson LW, Colton CK, Ford CA: Kinetics of hemodiafiltration. II. Clinical characterization of a new blood cleansing modality. J Lab Clin Med 85:372-391, 1975.

[13] Henderson LW: Biophysics of ultrafiltration and hemofiltration, in Replacement of renal function by dialysis, edited by Jacobs C, Kjellstrand CM, Koch KM, Winchester JF, 4th ed, Dordrecht, Kluwer Academic Publisher, 1996, pp 114-145.

[14] Hoenich NA, Woffindin C, Ronco C: Haemodialysers and associated devices, in Replacement of renal function by dialysis, edited by Jacobs $\mathrm{C}$, Kjellstrand CM, Koch KM, Winchester JF, 4th ed, Dordrecht, Kluwer Academic Publisher, 1996, pp 188-230. 
[15] Fresenius: Product brochure: Hemoflow F-series Fresenius Polysulfone Capillary Dialysers.

[16] Ronco C: Hemofiltration and hemodiafiltration, in Contemp Issues in Nephrol (vol 27), edited by JP B, New York, Churchill-Livingstone, 1993, pp 119-133.

[17] Sargent JA, Gotch FA: Principles and biophysics of dialysis, in Replacement of renal function by dialysis, edited by Jacobs C, Kjellstrand CM, Koch KM, Winchester JF, 4th ed, Dordrecht, Kluwer Academic Publishers, 1996, pp 34-102.

[18] Jaffrin MY, Ding LH, Laurent JM: Simultaneous convective and diffusive mass transfers in a hemodialyser. J Biomech Eng 112:212-219, 1990.

[19] Eloot S: Experimental and Numerical Modeling of Dialysis, in Civil Engineering Department, Gent, Ghent University, 2004, p 350.

[20] Vander Velde C, Leonard EF: Theoretical assessment of the effect of flow maldistributions on the mass transfer efficiency of artificial organs. Med Biol Eng Comput 23:224-229, 1985. 